\title{
Stimulatory Effects of L-5-Hydroxytryptophan on Postdexamethasone $\beta$-Endorphin Levels in Major Depression
}

\author{
Michael Maes, M.D., Ph.D., Ann Van Gastel, M.D., Rakesh Ranjan, M.D., Pierre Blockx, \\ Paul Cosyns, M.D., Herbert Y. Meltzer, M.D., and Roger Desnyder, M.D.
}

Recently it has been shown that acute administration of 200 $m g$ L-5-hydroxytryptophan (L-5-HTP) PO may increase post-dexamethasone (DST) adrenocorticotropic hormone (ACTH) and cortisol levels in major, but not minor, depressed subjects. This study aimed to examine the effects of $200 \mathrm{mg}$ L-5-HTP PO on post-DST $\beta$-endorphin levels in the same depressed subjects. It was found that in major, but not minor, depressed subjects, L-5-HTP significantly increased post-DST $\beta$-endorphin concentrations as compared to placebo. The L-5-HTP-induced post-DST $\beta$-endorphin responses were significantly higher in major than in minor depressed subjects. There was a significant and positive relationship between $L-5$-HTP-induced post$D S T \beta$-endorphin and ACTH or cortisol responses. There was a significant and positive relationship between $L-5$-HTP-induced post-DST $\beta$-endorphin values and the Hamilton Depression Rating Scale (HDRS) score. The results show that the acute administration of L-5-HTP may increase the escape of $\beta$-endorphin secretion from suppression by dexamethasone in major, but not minor, depression. [Neuropsychopharmacology 15:340-348, 1996]
KEY WORDS: Depression; Serotonin; 5-Hydroxytryptophan; $\beta$-Endorphin; Cortisol; ACTH; Dexamethasone suppression test

There is now some evidence that major depression is accompanied by an increased activity of the hypothalamic-pituitary-adrenal (HPA) axis (Carroll 1980; Maes et al. 1989, 1991b, 1994), disorders in peripheral and central serotonergic activity (Maes and Meltzer 1995), and by multiple reciprocal relationships between cen-

From the University Department of Psychiatry (MM, AVG, RD) AZ Stuivenberg, Belgium; the Laboratory of Biological Psychiatry (MM, RR, HYM), Case Western Reserve University, Cleveland; the Laboratory of Nuclear Medicine (PB), University Hospital of Antwerp, Belgium; and the Department of Psychiatry (MM, PC), UZA Antwerp, Belgium.

Address correspondence to: Michael Maes, M.D., Ph.D., Director CRC-MH, University Department of Psychiatry, AZ Stuivenberg, 267 Lange Beeldekensstraat, 2060 Antwerp, Belgium.

Received July 13, 1995; revised October 23, 1995; accepted October 25,1995 . tral and peripheral serotonergic activity and HPA-axis hyperactivity (Maes and Meltzer 1995).

One of the most consistently reported signs of HPAaxis hyperactivity in major depression is the failure to suppress plasma adrenocorticotropic hormone (ACTH) and cortisol following the overnight $1 \mathrm{mg}$ dexamethasone suppression test (Carroll 1980; Maes et al. 1989, 1991b). Because highly significant positive relationships were detected between postdexamethasone (DST) intact ACTH and cortisol in major depression, it has been suggested that the pathological escape of cortisol from suppression by dexamethasone is determined, in part, by that in pituitary ACTH (Maes et al. 1991b, 1993, 1994).

To examine the physiopharmacological interactions between the disorders in negative feedback on the HPA axis and serotonergic activity in depression, we studied the effects of L-5-hydroxytryptophan (L-5-HTP), the precursor of serotonin (5-HT), on post-DST ACTH and cortisol values in that illness (Maes et al. 1991a, 1995). It 
was found that (1) acute administration of L-5-HTP (125 $\mathrm{mg}$ or $200 \mathrm{mg}$ PO) significantly increased the escape of $\mathrm{ACTH}$ and, consequently, cortisol from suppression by dexamethasone; and (2) that this stimulatory effect of L-5-HTP was significantly greater in major than in minor (i.e., dysthymia, adjustment disorder with depressed mood) depression (Maes et al. 1991a, 1995). There is now some evidence that L-5-HTP-induced $\mathrm{ACTH}$ and cortisol responses in man and the rodent are mediated, at least in part, by $5-\mathrm{HT} 2 \mathrm{~A} / 2 \mathrm{C}$ and 5 -HT1A receptors (Nakagami et al. 1986; Rivier and Plotsky 1986; Van de Kar et al. 1989; Fuller 1992; Calogero et al. 1993; Chaouloff 1993; Meltzer and Maes 1994). Because there is some evidence that major depression is accompanied by an upregulation of 5-HT2A and a downregulation of 5-HT1A receptors (review in Maes and Meltzer 1995), it has been argued that the L-5-HTP-induced post-DST ACTH responses in major depression are related to the upregulation of 5-HT2A receptors in that illness (Maes et al. 1995).

$\mathrm{ACTH}$ and $\beta$-endorphin are derived from the same precursor, proopiomelanocortin. They may be secreted simultaneously from pituitary cells, and they may respond to the same stimuli (Guillemin et al. 1977; Mains et al. 1977; Dean et al. 1986). There is evidence that 5-HT exerts a stimulatory control over pituitary release of $\mathrm{ACTH}$ and $\beta$-endorphin in rodents and human subjects (e.g., Fukata et al. 1984; Petraglia et al. 1984; AbouSamra et al. 1985; Cancela et al. 1985; Majeed et al. 1985a, 1985b; Sapun-Malcolm et al. 1986). 5-HT reuptake inhibitors, 5-HTP, mCPP (a 5- $\mathrm{HT}_{2}$ receptor agonist), and fenfluramine (a 5-HT-releasing agent) have been shown to decrease $\beta$-endorphin content in the pituitary of rats (Cella et al. 1983; Majeed et al. 1985b). Therefore, it was concluded that serotonergic activation stimulates the release of $\beta$-endorphin from rat pituitary (Cella et al. 1983; Majeed et al. 1985a, 1985b).

Other studies also report a suppression of plasma $\beta$-endorphin levels by dexamethasone (Krantz and Brown 1985; Gispen-de-Wied et al. 1987). This suppression may parallel the suppression of plasma ACTH levels following dexamethasone administration (Wiedemann et al. 1979; Smith et al. 1981; Maes et al. 1991b, 1994). Some (Gispen-de-Wied et al. 1987; Maes et al. 1990), but not all (Lin et al. 1986; Ball et al. 1987), found a higher escape of plasma $\beta$-endorphin in major depressed subjects than in normal controls or DST cortisol nonsuppressors versus suppressors. In rats, it has been shown that pretreatment with dexamethasone blocks the $\beta$-endorphin responses to $\mathrm{MCPP}$ and 8-OH-DPAT, a $5-\mathrm{HT}_{1 \mathrm{~A}}$ agonist (Bagdy et al. 1990). However, no research has investigated the effects of 5-HT precursors on the post-DST $\beta$-endorphin values in patients with major depression.

The present study was carried out to examine the effects of L-5-HTP on post-DST $\beta$-endorphin values in major versus minor depressed subjects. Post-DST/L-5HTP $\beta$-endorphin responses were measured in the same major and minor depressed subjects for whom measurements of post-DST/L-5-HTP ACTH and cortisol had been obtained (Maes et al. 1995). It was hypothesized that L-5-HTP has a significant stimulatory effect on post-DST $\beta$-endorphin values in major, but not minor, depression.

\section{SUBJECTS AND METHODS}

\section{Subjects}

The study group consisted of 57 unipolar depressed subjects admitted to the psychiatric ward of the University Hospital of Antwerp between September 1991 and November 1992. Subjects were classified according to DSM-III-R criteria (APA 1980) into three groups: (1) dysthymic disorder or adjustment disorder with depressed mood, labeled as minor depression; (2) major depression without melancholia or simple major depression; and (3) major depression with melancholia. Diagnoses were made using the Structured Clinical Interview for DSM-III Patient Version (SCID; Spitzer et al. 1985). The severity of illness was measured using the 17-item Hamilton Depression Rating Scale (HDRS; Hamilton, 1960). Clinical assessments of the subjects were always carried out by the same rater 1 week after admission of the patients into hospital and immediately prior to L-5-HTP testing. We have excluded (1) subjects who were treated with lithium, monoamine oxidase inhibitors, and/or antipsychotic dosages of neuroleptics the year prior to admission; (2) subjects with other axis-I diagnoses besides unipolar depression, such as psychotic disorders, bipolar disorders, organic mental, and substance use disorder); (3) subjects with abnormal routine tests, such as radiograph of heart and lungs, electrocardiogram and electroencephalogram, chemical and hematological tests including blood, serum creatinine, SGPT, SGOT, $\gamma \mathrm{GT}$, serum electrolytes, erythrocyte sedimentation rate, hemoglobin, hematocrit, and coagulation tests; and (4) subjects with medical illnesses (e.g., endocrine disorders such as thyroid disorders, diabetes mellitus) and allergic or infectious disorders during the 2 weeks prior to blood samplings.

Table 1 lists the drug state of the subjects. Twentyfour subjects had been taking antidepressants, such as imipramine, nortriptyline, amitriptyline, maprotiline, viloxazine, the month prior to admission. Subjects who had taken selective serotonin reuptake inhibitors (SSRIs), such as fluoxetine or fluvoxamine, the month prior to admission were excluded from this study. Twentynine subjects had been taking benzodiazepines, and eight subjects had been taking a low dosage of neuroleptics the month prior to hospital admission. Twentynine subjects were treated with a low dosage of benzo- 
diazapines (equivalent of $15 \mathrm{mg}$ di-K-chlorazepate) during the study span.

\section{Methods}

Eight days after admission a catheter was inserted in the antecubital vein of the subjects at 7:30 A.M. EDTA plasma was sampled at 8:00 A.M. for $\beta$-endorphin assay. The same day subjects ingested $1 \mathrm{mg}$ dexamethasone at 11:00 P.M. The next day, a catheter was inserted at 7:30 A.M. and plasma was sampled at 8:00 A.M. for post-DST $\beta$-endorphin assay (Maes et al. 1990). Immediately after catheter placement, subjects ingested $200 \mathrm{mg} \mathrm{L-5-HTP}$ in nonenteric coated tablets or indistinguishable placebo. Administration of L-5-HTP or placebo were stratified: The first of two minor and the first of four major depressed subjects received placebo (in our hospital, admission statistics show that the number of major depressed subjects is three to four times higher than that of minor depressed subjects). Plasma was sampled at 9:00 A.M., 9:30 A.M., and 10:00 A.M. for assay of postDST/L-5-HTP $\beta$-endorphin values. Dexamethasone levels were determined at 8:00 A.M. and 9:30 A.M. Subjects were not allowed to eat or drink during the study; they remained supine during the study period. Plasma $\beta$-endorphin is determined by means of the Allégro$\beta$-Endorphin kit, which is an immunoradiometric assay (Nichols Institute, San Juan Capistrano, CA). The sensitivity of the assay is $5 \mathrm{pg} / \mathrm{mL}$. The analytical interassay $\mathrm{CV}$ in our laboratory is $10.4 \%$ (mean $=55 \mathrm{pg} / \mathrm{mL}, n=14)$. The percent crossreactivity with $\beta$-lipotropin is $16 \%$. Thus, this assay for immunoreactive $\beta$-endorphin also detects its biosynthetic precursor, $\beta$-lipotropin. Plasma dexamethasone is determined by a radioimmunoassay method (antibodies from Laboratoire d'Hormonologie, Marloie, Belgium) at the Dr. Willems Institute (University of Diepenbeek, Belgium). The analytical intraassay $\mathrm{CV}$ in our laboratory is $10.0 \%$ (mean $=2.44 \mathrm{ng} / \mathrm{mL}$ ). The lower limit of detection is $0.15 \mathrm{ng} / \mathrm{mL}$.

\section{Statistics}

Relationships between variables were assessed by means of Pearson's product-moment correlation coefficients or through multiple regression analyses. The independence of classification systems was ascertained by means of analysis of contingency ( $\chi^{2}$ test). Group mean differences were checked by means of analysis of variance (ANOVA) or covariance (ANCOVA). Multiple post hoc comparisons between group means were assessed by means of Fisher's least significant difference (LSD). Repeated-measures ANOVAs were used to compare hormonal values before and after challenge with L-5-HTP or placebo. The post-DST/L-5-HTP $\beta$-endorphin values were assessed in three different ways: (1) peak hormone responses after administration of L-5HTP; (2) area-under-the-curve (AUC) hormone responses, that is, area under the time $\times$ concentration curve from 8:00 A.M. to 10:00 A.M. (computed using the trapezoid method); and (3) $\triangle$ AUC hormone response, that is, AUC response - post-DST hormone values $\times$ $120 \mathrm{~min}$. The normality of distribution was checked by means of the Kolmogorov-Smirnov test. Box-Cox transformations of the post-DST, post-DST/L-5-HTP, and AUC responses were used in correlation and regression analyses and in ANOVAs or ANCOVAs to achieve normality of distribution and to adjust for heterogeneity of variance between diagnostic groups, respectively.

\section{RESULTS}

Table 1 shows the demographic data of the 57 subjects in this study. There were no significant differences in men:women ratio between minor and major depressed subjects $\left(\chi^{2}=0.00, p=.9\right)$. There were no significant differences in age between both diagnostic groups $(F=$ $1.4, \mathrm{df}=1 / 55, p=.2$ ). The HDRS score was significantly higher in major than in minor depressed subjects $\left(F=50.8, \mathrm{df}=1 / 55, p<10^{-4}\right)$. A $\chi^{2}$ test revealed no significant differences between minor and major depressed subjects in use of antidepressants $\left(\chi^{2}=3.7\right.$, $\mathrm{df}=1, p=.053)$, benzodiazepines $\left(\chi^{2}=0.1, \mathrm{df}=1, p=\right.$ $.7)$, or neuroleptics $\left(\chi^{2}=0.4, \mathrm{df}=1, p=.5\right)$ the month prior to the 8-day washout period. There were no significant differences in use of a low-dosage of benzodiazepines during the study span $\left(\chi^{2}=.04, \mathrm{df}=1, p=.8\right)$ or between the four drug state variables and any of the

Table 1. Demographic Data of the 57 Subjects

\begin{tabular}{llccccccc}
\hline & & & & & \multicolumn{3}{c}{ Drug State (yes/no ratio) $^{b}$} \\
\cline { 5 - 9 } Category & Index & Men/Women & Age (years) & HDRS $^{a}$ & AD & BZ1 & NL & BZ2 \\
\hline Minor depression & md & $3 / 13$ & $45.2(13.4)$ & $13.8(2.6)$ & $3 / 13$ & $7 / 9$ & $1 / 15$ & $8 / 8$ \\
Major depression & MD & $9 / 32$ & $50.2(14.6)$ & $23.3(5.1)$ & $21 / 20$ & $22 / 19$ & $7 / 34$ & $21 / 20$ \\
Without melancholia & MD - M & $4 / 13$ & $51.4(14.1)$ & $19.6(3.3)$ & $9 / 8$ & $8 / 9$ & $3 / 14$ & $9 / 8$ \\
With melancholia & MD + M & $5 / 19$ & $49.3(15.1)$ & $26.0(4.4)$ & $12 / 12$ & $14 / 10$ & $4 / 20$ & $12 / 12$ \\
\hline
\end{tabular}

${ }^{a}$ HDRS: Hamilton Depression Rating Scale (17 item).

${ }^{b}$ Drug state: Use of antidepressants (AD), benzodiazepines (BZ1), and antipsychotic agents (NL) the month prior to the 8-day washout period, and use of a low-dosage of benzodiazepines during the study span (BZ2). Results are shown as mean SD. 
Table 2. Measurements of Basal Postdexamethasone (DST) and Post-DST /L-5-HTP $\beta$-Endorphin (END) Levels in the 57 Subjects

\begin{tabular}{|c|c|c|c|c|c|c|}
\hline \multirow[b]{2}{*}{ Index, Treatment } & \multirow[b]{2}{*}{$n$} & \multicolumn{5}{|c|}{$\beta$-Endorphin Levels (pg/mL) } \\
\hline & & Basal & $\mathbf{D S T}^{a}$ & Peak DST/L-5-HTP ${ }^{a}$ & $\mathbf{A U C}^{a}$ & $\Delta \mathrm{AUC}^{a}$ \\
\hline \multicolumn{7}{|l|}{ Minor depression } \\
\hline Placebo & 5 & $53.6(23.5)$ & $7.0(2.5)$ & $7.8(1.8)$ & $837(178)$ & $-3(163)$ \\
\hline L-5-HTP & 11 & $20.3(9.4)$ & $11.3(6.3)$ & $11.3(5.4)$ & $1,238(651)$ & $-114(261)$ \\
\hline \multicolumn{7}{|l|}{ Major depression } \\
\hline Placebo & 8 & $28.5(12.2)$ & $9.0(4.0)$ & $9.2(4.6)$ & $1,041(492)$ & $-65(147)$ \\
\hline L-5-HTP & 33 & $30.4(15.0)$ & $11.0(7.6)$ & $16.8(8.9)$ & $1,613(930)$ & $297(418)$ \\
\hline \multicolumn{7}{|l|}{ ANCOVAs: $F$ ( $p$ value) } \\
\hline Minor versus major depression & & $0.0(9.0)$ & $0.4(0.6)$ & $1.2(0.3)$ & $0.9(0.7)$ & $1.5(0.2)$ \\
\hline Placebo/5-HTP & & - & - & $4.3(0.03)$ & $3.3(0.07)$ & $0.6(0.6)$ \\
\hline Interaction & & - & - & $4.7(0.03)$ & $4.6(0.03)$ & $5.0(0.02)$ \\
\hline Age & & $0.2(0.7)$ & $6.3(0.01)$ & $2.3(0.1)$ & $1.5(0.2)$ & $4.7(0.03)$ \\
\hline Sex & & $10.3(0.003)$ & $0.0(0.9)$ & $0.6(0.5)$ & $0.5(0.5)$ & $0.0(0.9)$ \\
\hline Basal & & - & $5.7(0.02)$ & - & - & - \\
\hline DST & & - & - & $61\left(<10^{-4}\right)$ & $131\left(<10^{-4}\right)$ & - \\
\hline
\end{tabular}

${ }^{a}$ These values are processed in Box-Cox transformation. AUC: area under the time-concentration curve from 8:00 A.M. to 10:00 A.M. (computed using the trapezoid method); $\triangle$ AUC: area under the time-concentration curve minus post-DST endorphin values $\times 120$ minutes. All results are listed as mean $\pm \mathrm{SD}$.

$\beta$-endorphin data. For example, the regression of $\Delta$ AUC $\beta$-endorphin on the four drug state variables was not significant $(F=.3, \mathrm{df}=4 / 39, p=.8)$, and none of the regression coefficients for use of antidepressants $(F=$ $.0, p=.9)$, benzodiazepines $(F=.5, p=.5)$, and neuroleptics $(F=.6, p=.6)$ prior to the study and benzodiazepines during the study $(F=0, p=.9)$ were significant. Thus, there is no evidence for major effects of the drug state of the subjects. In addition, subsequent statistical analyses were checked for possible effects of use of antidepressants prior to the washout period (e.g., by employing use of antidepressants as a covariate in ANCOVAs).

There were no significant relationships between age and peak post-DST/L-5-HTP $\beta$-endorphin $(r=.07, p=$ .6) and post-DST/L-5-HTP AUC $\beta$-endorphin $(r=-.05$, $p=.7)$. There was, however, a positive relationship between age and $\Delta$ AUC post-DST/L-5-HTP $\beta$-endorphin $(r=.38, p=.01)$. There were no gender differences in peak post-DST $/ \mathrm{L}-5$-HTP $\beta$-endorphin $(F=1.6, \mathrm{df}=1 / 42$, $p=.2)$, AUC post-DST /L-5-HTP $\beta$-endorphin $(F=1.4$, $\mathrm{df}=1 / 42, p=.2), \Delta$ AUC post-DST $/$ L-5-HTP $\beta$-endorphin $(F=0, \mathrm{df}=1 / 42, p=.9)$, post-DST $\beta$-endorphin $(F=2.6, \mathrm{df}=1 / 42, p=.1)$, or basal $\beta$-endorphin $(F=$ $3.9, \mathrm{df}=1 / 42, p=.052)$ concentrations. Nevertheless, we have adjusted all subsequent statistical analyses for possible age and gender effects by introducing age and sex as covariates in ANCOVAs or multiple regression analyses.

Table 2 shows the measurements of basal, post-DST, peak post-DST/L-5-HTP, AUC post-DST/L-5-HTP, and $\triangle$ AUC post-DST/L-5-HTP $\beta$-endorphin. We used ANCOVA with age and sex as covariates and the diagnostic and placebo versus L-5-HTP-treated categories as groups.
Significant higher basal $\beta$-endorphin values were detected in the minor depressed subjects who received placebo than in all other subjects. $(F=4.3, \mathrm{df}=1 / 52, p=.04$; Fisher's LSD at $p=.05)$. In any case, subsequent results on post-DST/L-5-HTP $\beta$-endorphin values are not influenced by these differences, because post-DST $\beta$-endorphin values were not significantly different between the diagnostic and placebo- versus L-5-HTP-treated categories (i.e., ANCOVA results with age and sex as covariates and diagnostic and placebo- versus L-5-HTP-treated categories as groups). Repeated-measures ANOVA revealed a significant suppressant effect of dexamethasone $\left(F=119, \mathrm{df}=1 / 55, p<10^{-4}\right)$ on $\beta$-endorphin values. There were no significant differences in basal or post-DST $\beta$-endorphin values between minor and major depression. Repeated-measures ANOVA also showed a significant effect of L-5-HTP on post-DST $\beta$-endorphin values $(F=4.9, \mathrm{df}=1 / 54, p=.03)$, a significant difference between the placebo and L-5-HTP condition $(F=6.9, \mathrm{df}=$ $1 / 54, p=.01)$, and a significant interaction between time $\times$ L-5-HTP/placebo treatment $(F=4.5, \mathrm{df}=1 / 54$, $p=.04)$. Subjects challenged with L-5-HTP $(n=44)$, a significant effect of L-5-HTP on $\beta$-endorphin values was observed $(F=11.0, \mathrm{df}=1 / 42, p=.002)$, and a significant interaction between time $\times$ diagnosis $(F=9.4$, $\mathrm{df}=1 / 42, p=.004)$.

Table 2 shows the results of ANCOVA with peak post-DST/L-5-HTP $\beta$-endorphin values as dependent variable and post-DST $\beta$-endorphin, age, and sex as covariates. This analysis shows significant differences in the actual post-DST $\beta$-endorphin responses to L-5-HTP compared to placebo, as well as a significant interaction between diagnostic classification and placebo/L-5-HTP 


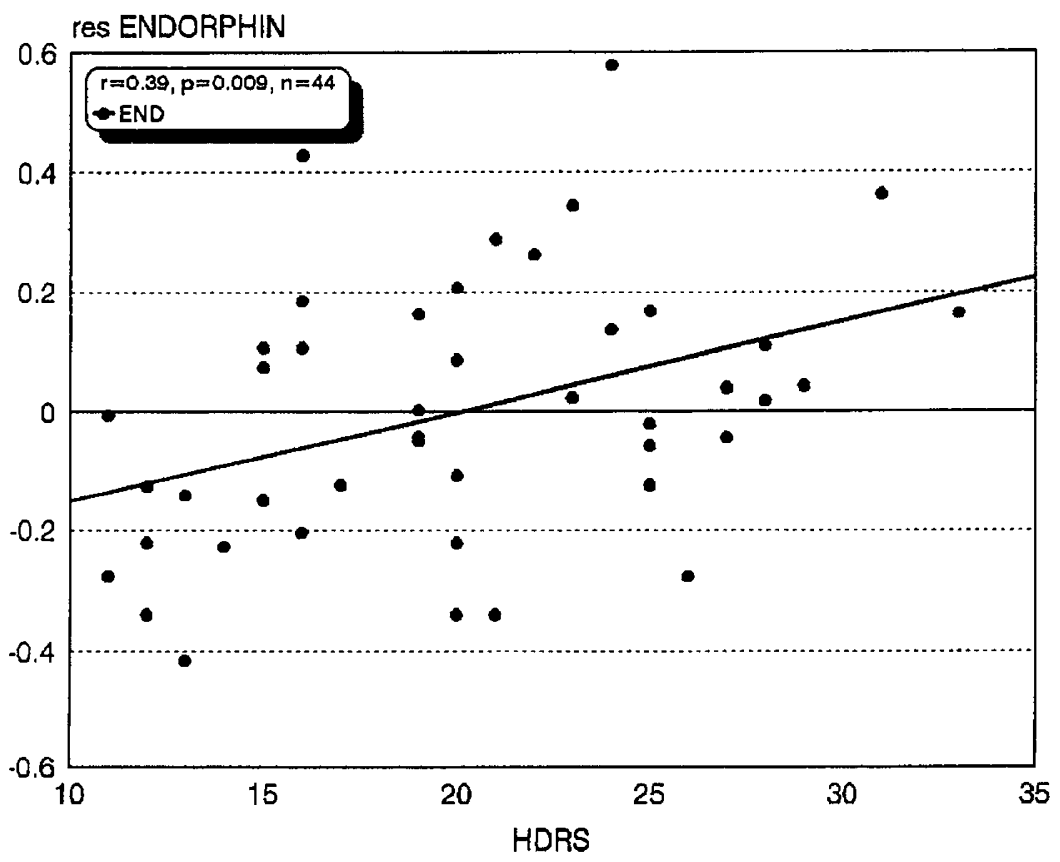

Figure 1. Regression of the actual L-5-HTPstimulated post-DST $\beta$-endorphin responses on the HDRS score. The former was computed as the residualized values obtained after regression of the peak post-DST/L-5-HTP $\beta$-endorphin on the post-DST $\beta$-endorphin values.

treatment. A significant interaction between diagnosis and placebo/L-5-HTP treatment was also found in the ANCOVAs with (1) AUC post-DST/L-5-HTP or placebo $\beta$-endorphin responses as dependent variable and post-DST $\beta$-endorphin, age, and sex as covariates (assessing the actual AUC $\beta$-endorphin responses); and with (2) the $\triangle$ AUC $\beta$-endorphin values as dependent variable and age and sex as covariates. These results do not change after covarying for use of antidepressants prior to the washout period (entered as a dummy variable). For example, an ANCOVA with post-DST $\beta$-endorphin and use of antidepressants as covariates and peak postDST/L-5-HTP as dependent variable showed a significant difference between L-5-HTP and placebo treatment $(F=4.6, \mathrm{df}=1 / 51, p=.03)$ and a significant interaction effect between diagnosis and placebo/L-5-HTP treatment $(F=4.0, \mathrm{df}=1 / 51, p=.04)$. In the L-5-HTP-treated subjects, significantly higher peak post-DST/L-5-HTP $\beta$-endorphin responses were found in major than in minor depression (ANCOVA with post-DST $\beta$-endorphin as covariate: $F=9.8, \mathrm{df}=1 / 41, p=.004$; in minor: $0.00 \pm$ $3.1 \mathrm{pg} / \mathrm{mL}$ versus major depression: $5.90 \pm 6.24 \mathrm{pg} /$ $\mathrm{mL}$ ). These differences remained significant after antidepressants were introduced before the washout period as a covariate $(F=7.6, \mathrm{df}=1 / 40, p=.009)$.

In the subjects treated with L-5-HTP, there were significant and positive relationships between HDRS and peak post-DST/L-5-HTP $(F=5.8, p=.02)$ and AUC post-DST/L-5-HTP $(F=6.2, p=.01) \beta$-endorphin values (all results of multiple regression analyses with post-DST $\beta$-endorphin values as additional covariate). Figure 1 shows the relationship between the HDRS score and the residualized post-DST/L-5-HTP $\beta$-endorphin values (after regression on post-DST $\beta$-endorphin).
In the total study group $(n=57)$, no significant relationships were found between post-DST $\beta$-endorphin and the 8:00 A.M. dexamethasone values $(r=-.11, p=$ .6). In the L-5-HTP-treated subjects $(N=44)$, no significant relationships were found between peak post-DST / L-5-HTP $\beta$-endorphin values and either 8:00 A.M. ( $\mathrm{r}=$ $-.24, p=.11)$ or 9:30 A.M. ( $r=.17, p=.3$ ) dexamethasone values. Repeated-measures ANOVA on the 8:00 A.M. and 9:30 A.M. dexamethasone values, showed significantly lower dexamethasone values at 9:30 A.M. than at 8:00 A.M. $\left(F=31.4, p=1 / 55, p<10^{-4} ; 1.72 \pm 1.17 \mathrm{ng} /\right.$ $\mathrm{mL}$ versus $2.08 \pm 1.29 \mathrm{ng} / \mathrm{mL}$ ). The interaction pattern between time $\times$ placebo/L-5-HTP treatment was not significant in this repeated-measures ANOVA $(F=2.2$, $\mathrm{df}=1 / 55, p=.1)$. Moreover, ANCOVA with the $\triangle$ AUC post-DST/L-5-HTP values as dependent variable and age $(F=5.8, p=.02)$, sex $(F=0, p=.9)$ and 9:30 A.M. dexamethasone $(F=1.7, p=.2)$ as covariates, showed a significant interaction pattern between diagnosis and placebo/L-5-HTP treatment $(F=4.1, p=.04)$. These results show that (1) dexamethasone pharmacokinetics between 8:00 and 9:30 A.M. are probably not influenced by L-5-HTP administration; and (2) dexamethasone does not interfere with the results we obtained showing that L-5-HTP administration increases post-DST $\beta$-endorphin concentration in major, but not minor, depression.

We examined the relationships between the postDST/L-5-HTP $\beta$-endorphin values, determined in the present study, and the post-DST/L-5-HTP ACTH and cortisol values, described in our previous report (Maes et al. 1995). There were significant and positive relationships between peak post-DST/L-5-HTP $\beta$-endorphin and cortisol $(r=.48, p=.001)$ and ACTH $(r=.58$, 
$p=.0001$ ) values. There were significant and positive relationships between the actual L-5-HTP-induced peak post-DST $\beta$-endorphin and ACTH $(r=.48, p=.001)$ and cortisol $\left(r=.59, p<10^{-4}\right)$ responses (the actual responses were computed as the residualized values obtained after regression of the post-DST/L-5-HTP on their post-DST hormone values).

\section{DISCUSSION}

The major finding of this study is that acute administration of L-5-HTP augments the escape of $\beta$-endorphin from suppression by dexamethasone in major, but not minor, depression. This study reports that L-5-HTP has a significant stimulatory effect on post-DST $\beta$-endorphin values versus placebo in major depressed subjects, whereas in minor depression no such significant effect could be established. These differences between major and minor depression are related in part to differences in the severity of illness, because the actual L-5-HTPinduced $\beta$-endorphin responses were significantly and positively related to the severity of illness, as measured by the HDRS score.

The findings of this study extend those of previous reports that showed that L-5-HTP may augment the escape of ACTH and cortisol from suppression by dexamethasone in depression (Maes et al. 1991a, 1995) and that L-5-HTP has a greater effect on HPA-axis hormone secretion in major depression than in normal controls or minor depressed subjects (Meltzer et al. 1984; Maes et al. 1987). Moreover, a highly significant relationship between the L-5-HTP-induced post-DST $\beta$-endorphin and ACTH responses was found in depression. These findings suggest that the pathophysiological mechanisms underlying the increased L-5-HTP-stimulated post-DST $\mathrm{ACTH}$ and $\beta$-endorphin responses are partly related. It is hypothesized that the hyperresponsivity to $5-\mathrm{HT}$ following L-5-HTP administration at 5-HT2A postsynaptic receptor sites is involved in the pathologically increased L-5-HTP-stimulated ACTH/cortisol and post-DST/L-5HTP ACTH/cortisol responses in major depression (Meltzer et al. 1984; Maes et al. 1987, 1995; Maes and Meltzer 1995). The rationale for this hypothesis stems from the following. First, L-5-HTP-induced ACTH and cortisol responses in rodents and human subjects are mediated, at least in part, by $5-\mathrm{HT}_{2 \mathrm{~A} / 2 \mathrm{C}}$ and $5-\mathrm{HT}_{1 \mathrm{~A}}$ receptors (Nakagami et al. 1986; Rivier and Plotsky 1986; Van de Kar et al. 1989; Fuller 1992; Calogero et al. 1993; Chaouloff 1993). In particular, L-5-HTP-, mCPP-, and MK-212-induced HPA-axis hormone responses in normal volunteers are antagonized by ritanserin but are not blocked by pindolol (Meltzer and Maes 1994, in press a, in press b; Lee et al. 1991). Second, major depression is reportedly accompanied by an upregulation of $5-\mathrm{HT}_{2 \mathrm{~A}}$ and a downregulation of $5-\mathrm{HT}_{1 \mathrm{~A}}$ receptors (review in Maes and Meltzer 1995).

There is also some evidence that in rodents and human subjects 5-HT exerts a stimulatory control over the pituitary release of $\beta$-endorphin (Cella et al. 1983; Sapun-Malcolm et al. 1983, 1986; Petraglia et al. 1984; Abou-Samra et al. 1985; Cancela et al. 1985) and that activation of either $5-\mathrm{HT}_{1 \mathrm{~A}}$ or $5-\mathrm{HT}_{2}$ receptors results in $\beta$-endorphin secretion. Thus, acute administration of $5-\mathrm{HT}_{1 \mathrm{~A}}$ agonists, such as 8-OH-DPAT, ipsapirone, gepirone, and of $5-\mathrm{HT}_{2 \mathrm{~A} / 2 \mathrm{C}}$ agonists, such as $\mathrm{MCPP}$ and MK-212, may increase plasma $\beta$-endorphin in normal volunteers or in the rodent (Majeed et al. 1985a, 1985b; Koenig et al. 1987; Anderson et al. 1990; Bagdy et al. 1990; Di-Sciullo et al. 1990; Carr et al. 1991). MK-212induced $\beta$-endorphin secretion is not affected by pretreatment with pindolol, a $5-\mathrm{HT}_{1 \mathrm{~A}}$ receptor antagonist, but is attenuated by selective $5-\mathrm{HT}_{2}$ antagonists, such as ritanserin, ketanserin, and altanserin (Koenig et al. 1987). Also, the 8-OH-DPAT-stimulated $\beta$-endorphin secretion is antagonized by pindolol (Koenig et al. 1987). From the above it appears that 5-HT-acting drugs are able to stimulate $\beta$-endorphin secretion through stimulation of $5-\mathrm{HT}_{2 \mathrm{~A} / 2 \mathrm{C}}$ and $5-\mathrm{HT}_{1 \mathrm{~A}}$ receptors and that the control of serotonergic pathways on the release of POMC-derived peptides, such as ACTH and $\beta$-endorphin, is quite similar. There is evidence that major depression is accompanied by $5-\mathrm{HT}_{2 \mathrm{~A}}$ receptor upregulation and $5-\mathrm{HT}_{1 \mathrm{~A}}$ receptor downregulation (review in Maes and Meltzer 1995), so it may be hypothesized that the upregulation of $5-\mathrm{HT}_{2 \mathrm{~A}}$ receptors in that illness may participate in the exaggerated L-5-HTP-induced postDST $\beta$-endorphin responses. In healthy volunteers, however, 5- $\mathrm{HT}_{2 \mathrm{~A} / 2 \mathrm{C}}$ receptor blockade by ritanserin pretreatment did not affect 5-HTP-induced $\beta$-endorphin secretion, suggesting that the serotonergic activation of $\beta$ endorphin secretion in normal individuals is not regulated through 5- $\mathrm{HT}_{2}$ receptors (Facchinetti et al. 1987). To further examine the role of 5- $\mathrm{HT}_{2}$ receptors in L-5HTP-stimulated $\beta$-endorphin secretion in depression, the authors are studying the effects of acute administration of L-5-HTP on plasma $\beta$-endorphin in depressed subjects pretreated with dexamethasone and with ritanserin or placebo.

In the present study, there was a highly significant effect of dexamethasone administration on plasma $\beta$-endorphin levels. This is in accordance with previous findings (Wiedemann et al. 1979; Smith et al. 1981; Krantz and Brown 1985; Gispen-de-Wied et al. 1987; Maes et al. $1990,1991 b)$. The frequency of $\beta$-endorphin nonsuppression (defined as post-DST $\beta$-endorphin $\geq 22 \mathrm{pg} /$ $\mathrm{mL}$; Maes et al. 1990) in the present study was rather low, that is, $13.8 \%$, compared to that in our previous studies (e.g., Maes et al. 1990, 1991b). However, L-5HTP administration significantly increased the number of DST $\beta$-endorphin nonsuppressors from $13.8 \%$ to 
$30.3 \%(10 / 23)$ in major depressed subjects, whereas the frequency of DST $\beta$-endorphin nonsuppression remained unaltered by treatment with L-5-HTP in minor depression (i.e., 9\%). Thus, it appears that the acute administration of L-5-HTP can disclose disorders in the negative feedback of glucocorticoids on $\beta$-endorphin secretion in major, but not minor, depressed subjects.

The present study provides further evidence that pituitary ACTH and $\beta$-endorphin secretion may respond in parallel to the same stimuli. Thus, (1) post-DST plasma ACTH and $\beta$-endorphin values are strongly correlated in depression (Maes et al. 1991b, 1994); (2) the corticotropin-releasing-hormone- (CRH) induced ACTH and $\beta$-endorphin levels are highly correlated in normal volunteers and depressed subjects (Jackson et al. 1984; McLoughlin et al. 1984; Young et al. 1986; Maes et al. 1992); (3) the CRH-induced escape of plasma ACTH and $\beta$-endorphin from suppression by dexamethasone is highly intercorrelated in depressed subjects (Maes et al. 1994); (4) exogenous ACTH (i.e., Synacthen $250 \mu \mathrm{g}$ IV) suppresses both plasma ACTH and $\beta$-endorphin while the degree of suppression in both peptides is strongly interrelated. Melancholic subjects, however, exhibit a proportionally lower $\mathrm{CRH}$-induced ACTH response in relation to $\mathrm{CRH}$-induced $\beta$-endorphin responses (Maes et al. 1992; Rupprecht et al. 1989), suggesting that the release of both hormones is not always tightly coupled in all conditions.

There are, however, some weaknesses in this study. First, the number of subjects was small in the different subgroups, in particular in the minor depressed subjects treated with placebo. Second, our study did not use a placebo control condition in a cross-over design, which would have minimized sources of variance, thus, lowering the rate of type I error (Thompson et al. 1994). However, as explained, the placebo-controlled condition may be omitted when the baseline (i.e., post-DST hormone secretion) condition is well established (Thompson et al. 1994). Moreover, dexamethasone and L-5-HTP or their interactions may induce sequence or carry-over effects on HPA-axis hormone secretion and, consequently, placebo and active challenger (L-5-HTP) should be administered at random and with a time delay of at least 1 week. It is obvious that this will cause an increased probability of subject dropout (there is already a 1-week washout period) and a loss of the timely relationships between L-5-HTP challenge and diagnostic assessments in these acutely depressed inpatients. Therefore, we decided not to use a cross-over design with a placebo control condition, but rather to make comparisons between subjects on L-5-HTP versus placebo.

Third, plasma L-5-HTP levels were not measured in the present study, and, therefore, we cannot exclude possible differences in the pharmacokinetic properties of L-5-HTP between the diagnostic groups. However, our laboratory could not find any significant differences in plasma L-5-HTP levels after administration of 200 mg L-5-HTP PO in major depressed subjects with or without melancholia (in an acute phase of illness, partial remission, or remission) and normal volunteers (Meltzer and Maes, unpublished data).

In conclusion, this study shows that the acute administration of L-5-HTP significantly augments the escape of plasma $\beta$-endorphin from suppression by dexamethasone in major, but not in minor, depression. It is argued that this phenomenon may be caused by hyperresponsivity to $5-\mathrm{HT}$ at the postsynaptic $5-\mathrm{HT}_{2 \mathrm{~A}}$ receptor sites in major depression.

\section{ACKNOWLEDGMENTS}

The research reported was supported in part by the National Funds of Scientific Research (NFWO), Belgium, the UIAP Program, Antwerp, Belgium, and grants from the Elisabeth Severance Prentiss and John Pascal Sawyer Foundations and the Michael Kaplen Investigator Award to M. Maes. H. Y. Meltzer is the recipient of a USPHS Research Career Scientist Award MH 47808. The secretarial assistance of Mrs. M. Maes is greatly appreciated.

\section{REFERENCES}

Abou-Samra AB, Fevre-Montange M, Loras B, Durand A, Tourniaire J, Bertrand J (1985): Effect of indolamines on beta-endorphin release by rat anterior pituitary cells. Neuroendocrinology 41:490-493

American Psychiatric Association (1980): Diagnostic and Statistical Manual of Mental Disorders, ed. 3. Washington, DC, American Psychiatric Association

Anderson IM, Cowen PJ, Grahame-Smith DG (1990): The effects of gepirone on neuroendocrine function and temperature in humans. Psychopharmacology 100:498-503

Bagdy G, Calogero AE, Szemeredi K, Gomez MT, Murphy DL, Chrousos GP, Gold PW (1990): Beta-endorphin responses to different serotonin agonists: Involvement of corticotropin-releasing hormone, vasopressin and direct pituitary action. Brain Res 537:227-232

Ball R, Howlett T, Silverstone T, Rees L (1987): The interrelationship of beta endorphin, ACTH and cortisol in depressive illness: A controlled study. Psychol Med 17:31-37

Calogero AE, Bagdy G, Moncada ML, Dagata R (1993): Effect of selective serotonin agonists on basal, corticotrophinreleasing hormone-induced and vasopressin-induced ACTH release in vitro from rat pituitary cells. J Endocrinol 136:381-387

Cancela LM, Fulginiti S, Ramirez OA (1985): Involvement of a serotonergic control in the regulation of plasma levels of immunoreactive beta-endorphin. Acta Physiol Pharmacol Latinoam 35:409-413

Carr JA, Saland LC, Samora A, Benavidez S, Krobert K (1991): In vivo effects of serotonergic agents on alphamelanocyte-stimulating hormone secretion. Neuroendocrinology 54:616-622 
Carroll BJ (1980): Clinical application of neuroendocrine research in depression. In van Praag $\mathrm{HM}$, Lader $\mathrm{MH}$, Rafaelsen OJ, Sachar EJ (eds), Handbook of Biological Psychiatry, Part III: Brain Mechanisms and Abnormal Behavior-Genetics and Neuroendocrinology. New York, Marcel Dekker, pp 179-193

Cella S, Penalva A, Locatelli V, Novelli A, Cocchi D, Muller EE (1983): Neuroendocrine studies with fluvoxamine: Animal data. Br J Clin Pharmacol 15:357-364

Chaouloff F (1993): Physiopharmacological interactions between stress hormones and central serotonergic systems. Brain Res Rev 18:1-32

Dean B, Kolavcic M, Tizian L, Harrison L (1986): Should plasma $\beta$-endorphin be measured in patients with disorders of the hypothalamic-pituitary-adrenal axis? Clin Chem 32:895

Di-Sciullo A, Bluet-Pajot MT, Mounier F, Oliver C, Schmidt B, Kordon C (1990): Changes in anterior pituitary hormone levels after serotonin $1_{\mathrm{A}}$ receptor stimulation. Endocrinology 127:567-572

Facchinetti F, Martignoni E, Nappi G, Marini S, Petraglia F, Sandrini G, Genazzani AR (1987): Ritanserin, a serotonin-S2 receptor antagonist, does not prevent 5-hydroxytryptophan-induced beta-EP, beta-LPH and cortisol secretion. Horm Res 27:42-46

Fukata J, Nakai Y, Imura H, Takeuchi J (1984): Effects of serotonin depleters on the contents of beta-endorphin, alpha-melanotropin and adrenocorticotropin in rat brain and pituitary. Brain Res 324:289-293

Fuller RW (1992): The involvement of serotonin in regulation of pituitary-adrenocortical function. Front Neuroendocrinol 13:250-270

Gispen-de-Wied CC, Westenberg HG, Thijssen JH, Van Ree JM (1987): The dexamethasone and cortisol suppression test in depression: Beta-endorphin as a useful marker. Psychoneuroendocrinology 12:355-366

Guillemin R, Vargo T, Rossier J, Minick S. Ling N, Rivier C, Vale W, Bloom F (1977): $\beta$-endorphin and adrenocorticotropin are secreted concomitantly by the pituitary gland. Science 197:1367-1369

Hamilton M (1960): A rating scale for depression. J Neurol Neurosurg Psychiatry 23:56-61

Jackson RV, DeCherney GS, DeBold CR, Sheldon WR, Alexander AN, Rivier J, Vale W, Orth DN (1984): Synthetic ovine corticotropin-releasing hormone: Simultaneous release of proopiolipomelanocortin peptides in man. $\mathrm{J}$ Clin Endocrinol Metab 58:740-743

Krantz DE, Brown WA (1985): Dexamethasone suppresses beta-endorphin in humans. Psychoneuroendocrinology 10:211-214

Koenig JI, Gudelsky GA, Meltzer HY (1987): Stimulation of corticosterone and beta-endorphin secretion in the rat by selective 5-HT receptor subtype activation. Eur J Pharmacol 137:1-8

Lee MA, Nash JF, Barnes M, Meltzer HY (1991): Inhibitory effect of ritanserin on the 5-hydroxy-tryptophan-mediated cortisol, ACTH and prolactin secretion in humans. Psychopharmacology 103:258-264

Lin SC, Maruta T, Newman DC, Kao PC (1986): Plasma levels of cortisol, corticotropin, and beta endorphin in patients with major depression. J Clin Psychiatry 47:413-414
Maes M, Meltzer HYM (1995) The serotonin hypothesis of major depression. In Bloom FE, Kupfer DJ (eds), Psychopharmacology, the Fourth Generation of Progress. New York, Raven Press, pp 933-944

Maes M, De Ruyter M, Claes R, Bosma G, Suy E (1987): The cortisol responses to 5-hydroxytryptophan, orally, in depressive inpatients. J Affect Disord 13:23-30

Maes M, Vandewoude M, Schotte C, Cosyns P (1989): Results of the 8 A.M. dexamethasone suppression test constitute a suitable tool for confirming the diagnosis melancholia: A test unaffected by the variations in the bioavailability of dexamethasone. Neuropsychobiology $22: 26-32$

Maes M, Jacobs M-P, Suy E, Leclercq C, Christiaens F, Raus J (1990): An augmented escape of $\beta$-endorphins to suppression by dexamethasone in severely depressed patients. J Affect Disord 18:149-156

Maes M, D'Hondt P, Martin M, Claes M, Schotte C, Vandewoude M, Blockx P (1991a): L-5-hydroxytryptophan simulated cortisol escape from dexamethasone suppression in melancholic patients. Acta Psychiatr Scand 83:302-306

Maes M, Vandervorst C, Suy E, Minner B, Raus J (1991b): A multivariate study on the simultaneous urinary free cortisol, plasma cortisol, adrenocorticotropic hormone and $\beta$-endorphin escape from suppression by dexamethasone in melancholic patients. Acta Psychiatr Scand 83:480-491

Maes M, Claes M, Vandewoude M, Schotte C, Martin M, Blockx P, Cosyns P (1992): Adrenocorticotropin hormone, $\beta$-endorphin and cortisol responses to $\mathrm{OCRH}$ in melancholic patients. Psychol Med 22:317-329

Maes M, Meltzer HY, Cosyns P, Calabrese J, D'Hondt P, Blockx P, Vandervorst C, Raus J (1993): Pituitary and adrenal hormone responses to Synacthen in melancholic versus minor depressed subjects. Biol Psychiatry 33:624-629

Maes M, Meltzer HY, Cosyns P, Calabrese J, D'Hondt P, Blockx P (1994): Adrenocorticotropic hormone, $\beta$-endorphin and cortisol responses to oCRH in unipolar depressed patients pretreated with dexamethasone. Prog Neuro-Psychopharmacol Biol Psychiatry 18:1273-1292

Maes M, D'Hondt P, Meltzer HY, Cosyns P, Blockx P (1995): Effects of serotonin agonists on the negative feedback by glucocorticoids on the hypothalamic-pituitary-adrenal axis in depression. Psychoneuroendocrinol 20:149-167

McLoughlin L, Tomlin S, Grossman A, Lytras N, Schally AV, Coy D, Besser GM, Rees LH (1984): CRH-41 stimulates the release of $\beta$-lipotrophin and $\beta$-endorphin in normal human subjects. Neuroendocrinology 38:282-284

Mains RE, Eipper BA, Ling N (1977): Common precursor to corticotropins and endorphins. Proc Natl Acad Sci USA 74:3014-3018

Majeed NH, Lason W, Przewlocka B, Przewlocki R (1985a): Serotonergic regulation of the brain and gut beta-endorphin and dynorphin content in the rat. Pol J Pharmacol Pharm 37:909-918

Majeed NH, Lason W, Przewlocka B, Przewlocki R (1985b): Differential modulation of the beta-endorphin and dynorphin systems by serotonergic simulation in the rat. Neuropeptides 5:563-566

Meltzer HY, Maes M (1994): Effects of pindolol on 5-HTPinduced prolactin and cortisol responses. Psychopharmacol 114:635-643 
Meltzer HY, Maes M (in press a): Effects of pindolol on $\mathrm{mCPP}$-induced prolactin and cortisol responses in normal man. Psychiatr Res

Meltzer HY, Maes M (in press b): Effects of pindolol on MK212-induced cortisol and prolactin responses in normal men. Biol Psychiatry

Meltzer HY, Wiita B, Robertson A, Tricou BJ, Lowy M, Perline R (1984): Effect of 5-hydroxytryptophan or serum cortisol levels in major affective disorders: Enhanced response in depression and mania. Arch Gen Psychiatry 41:366-374

Nakagami Y, Suda T, Yajima F (1986): Effects of serotonin, cyproheptadine and reserpine on corticotropin-releasing factor release from rat hypothalamus in vitro. Brain Res 386:232-236

Petraglia F, Facchinetti F, Martignoni E, Nappi G, Volpe A, Genazzani AR (1984): Serotoninergic agonists increase plasma levels of beta-endorphin and beta-lipotropin in humans. J Clin Endocrinol Metab 59: 1138-1142

Rivier CL, Plotsky PM (1986): Mediation by corticotropin releasing factor (CRF) of adenohypophysial hormone secretion. Ann Rev Physiol 48:475-494

Rupprecht R, Lesch KP, Muller U, Beck G, Beckmann H, Schulte HM (1989): Blunted adrenocorticotropin but normal $\beta$-endorphin release after human corticotropinreleasing hormone administration in depression. J Clin Endocrinol Metab 69:600-603

Sapun-Malcolm D, Farah JM Jr, Mueller GP (1986): Serotonin and dopamine independently regulate pituitary beta- endorphin release in vivo. Neuroendocrinology 42:191196

Sapun-Malcolm D, Farah JM Jr, Mueller GP (1983): Evidence for serotonergic stimulation of pituitary beta-endorphin release: Preferential release from the anterior lobe in vivo. Life Sci 33:95-102.

Smith R, Grossman A, Gaillard R, Clement-Jones V, Ratter S, Mallinson J, Lowry PJ, Besser GM, Rees LH (1981): Studies on circulating met-enkephalin and $\beta$-endorphin: Normal subjects and patients with renal and adrenal disease. Clin Endocrinol 15:291-295

Spitzer RL, Williams JBW, Gibbon M (1985): Structured Clinical Interview for DSM-III Patient Version. New York, New York State Psychiatric Institute, Biometrics Research Department

Thompson PA, Maes M, Meltzer HY (1994): Use of placebo controlled models in neuroendocrine challenge studies in psychiatry research. Psychiatr Res 52:317-326

Van de Kar LD, Carnes M, Maslowski RJ, et al. (1989): Neuroendocrine evidence for denervation supersensitivity of serotonin receptors: Effects of the 5-HT agonist RU 24969 on corticotropin, corticosterone, prolactin and renin secretion. J Pharmacol Exp Ther 251:428-434

Wiedemann E, Saito T, Linfoot JA, Li CH (1979): Specific radioimmunoassay of human $\beta$-endorphin in unextracted plasma. J Clin Endocrinol Metab 49:478-480

Young EA, Lewis J, Akil H (1986): The preferential release of $\beta$-endorphin from the anterior pituitary lobe by corticotropin releasing factor (CRF). Peptides 7:603-607 